\title{
LIMITATIONS OF A SOIL WATER BUDGETING METHOD IN ESTIMATING GROUNDWATER RECHARGE WITH PARTICULAR REFERENCE TO THE DRY ZONE OF SRI LANKA
}

\section{R. P. DE SILVA}

Department of Agricultural \& Plantation Engineering, The Open University of Sri Lanka, Nugegoda.

(Accepted: 09 December 2004)

\begin{abstract}
An attempt was made to estimate ground water recharge with a simple soil water balance at 62 sampling points in 7 locations in the dry zone of Sri Lanka. These studies show that with the presently available hydrological data and information on processes like runoff, interception and preferential flow, the estimates are likely to show wide variation rather than single values and be of limited use. Also the estimates of recharge differ at least by $30 \%$ when different models are used to estimate actual evapotranspiration. The reasons behind these shortcomings in the application of the soil water budgeting method in the dry zone are discussed and measures to be adopted are identified for a soil water budgeting method to yield more meaningful estimates of recharge.
\end{abstract}

Key words: ground water recharge, soil water budget, Sri Lanka

\section{INTRODUCTION}

Despite the efforts by the government of Sri Lanka to provide water for irrigation, domestic and industrial uses for the dry zone by diverting the river Mahaweli, large areas remain without water during most parts of the year. Although more such irrigation schemes may be possible, a substantial area will still be short of water, especially during the dry months of the year.

Therefore, it is important that efforts are made to tap the groundwater resource. In fact this has already begun and a situation has developed where siting of wells have been based on ad-hoc methodologies. Senerath ${ }^{1}$ correctly points out that the development of groundwater resource has not been preceded or accompanied by systematic studies to evaluate the groundwater resources potential. A key parameter necessary to assess this potential is the rate of replenishment of the water table or recharge.

A number of methods are available for the estimation of recharge to an aquifer. ${ }^{2,3}$ Methods of estimating recharge can be broadly grouped into physical and chemical methods. Physical methods include (a) The use of lysimeters, (b) Soil Water Budget models, (c) Water table fluctuation

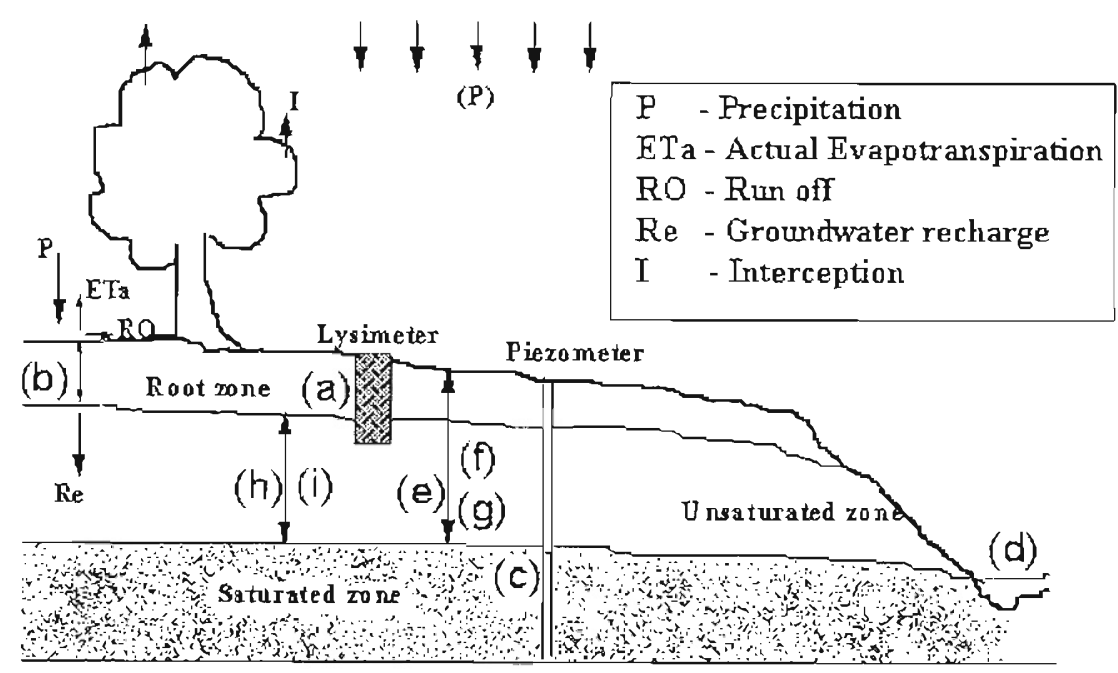

Figure1: Diagram showing the primary zone of focus of recharge estimation methods in the soil profile [(a) Lysimeters, (b) Soìl Water Budget, (c) Water table fluctuation method, (d) Catchment water balance method, (e) Numerical modelling of the unsaturated zone, (f) Zero flux plane method, (g) Darcy method, (h) Tritium method and (i) Chloride method] 
method, (d) Catchment water balance method, (e) Numerical modelling of the unsaturated zone, $(f)$ Zero flux plane method and (g) Darcy method. Chemical methods are (h) Tritium method and (i) Chloride method. The primary zones of focus of recharge estimation methods in the soil profile is shown in Fig. 1.

The soil water budgeting method is a simple method of estimating recharge often suitable under most conditions. ${ }^{4}$ Therefore, this paper assesses the suitability of using a soil water budgeting method to estimate recharge in the dry zone of Sri Lanka under the existing conditions.

\section{Soil water budgeting method}

In a soil water budget, the recharge is estimated as the residual of all the other fluxes in the hydrological cycle. The principle being that all these fluxes (i.e., precipitation, evapotranspiration, runoff, interception and soil moisture changes) are usually relatively more easily measured or estimated than recharge. Therefore, considering a volume of balance water in the root zone the recharge $\left(R_{e}\right)$ is estimated from

$R_{e}=P-I-R O-E T a+\Delta S$

where $\mathrm{P}$ is precipitation, $\mathrm{I}$ is interception of rainfall by vegetation, RO is runoff, ETa is actual evapotranspiration and $\Delta S$ is change in soil moisture storage. If the balance is carried out annually (or from an end of a rainy season to the end of another rainy season), it has been observed that the change in soil moisture storage is negligible. Therefore equation 1 reduces to;

$R_{e}=P-I-R O-E T a$

The basis for most soil water budgeting models is equation 2 . The differences result from the way other parameters (I, RO and ETa) are estimated. A discussion on estimating these parameters is found in published material by the author. $^{5}$

Table 1 summarises some instances of using a soil water budget method to estimate recharge in different parts of the world. From Table 1, it is seen that the root constant approach (i.e., Penman Grindley model) has been used in estimating actual evapotranspiration in Jordan, Uganda and Sri Lanka. Since the root constant and the drying curve depend on the climate, soils, and vegetation and also since this model has been developed for UK, it is necessary to consider the possible errors likely to creep in by simply adopting the Penman- Grindley model in estimating actual evapotranspiration for different conditions.

It is also seen from Table 1 that exact percentages (of rainfall) have been used to estimate some components (e.g., runoff), in some instances. However, it is more realistic to use a range (rather than an exact value) for these components, because it is difficult to know the exact values of these components. Therefore, it is interesting to see the effect of using a realistic range rather than an exact value for the components which are not known with any certainty, and this is investigated later in this paper.

\section{METHODS AND MATERLALS}

The methodology used to evaluate the suitability of a soil water budgeting method to estimate recharge in the dry zone is given below:

(a) Form a suitable soil water budget model.

(b) Collect both input data and calibration data necessary.

(c) Validate the model.

(d) Determine suitable values for model parameters.

(e) Estimate recharge with the soil water budget model.

(f) Compare with all available evidence on the reliability of recharge estimates by the soil water budget model.

Study areas: Seven locations (Fig. 2) were chosen to estimate recharge across the dry zone of Sri Lanka. As shown in Table 2, a number of sampling points were randomly chosen to estimate recharge in each location. Details of climate, soils and vegetation of each location are also given in Table 2 and more details of the locations are given in a previous publication by the author. ${ }^{5}$ 


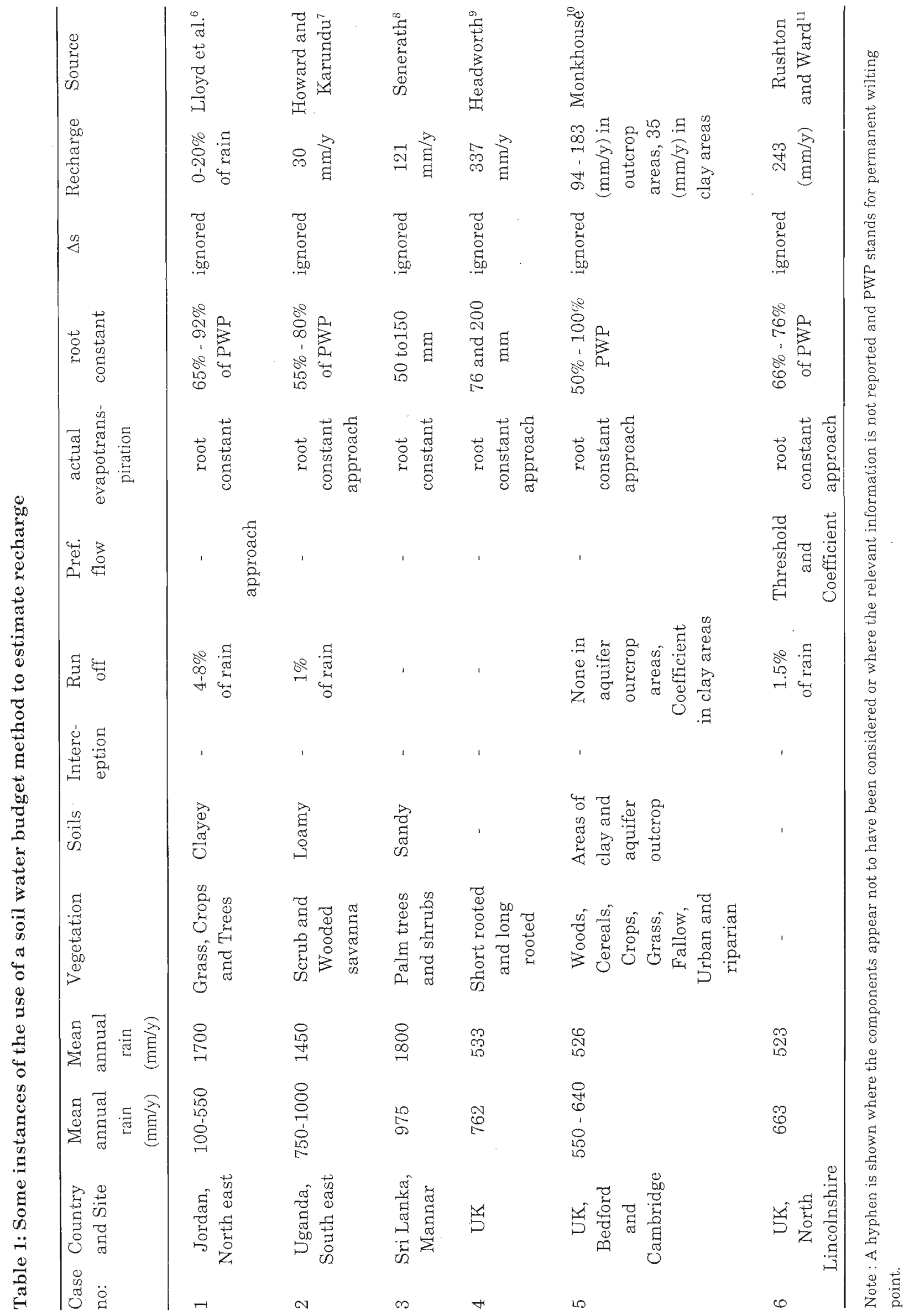




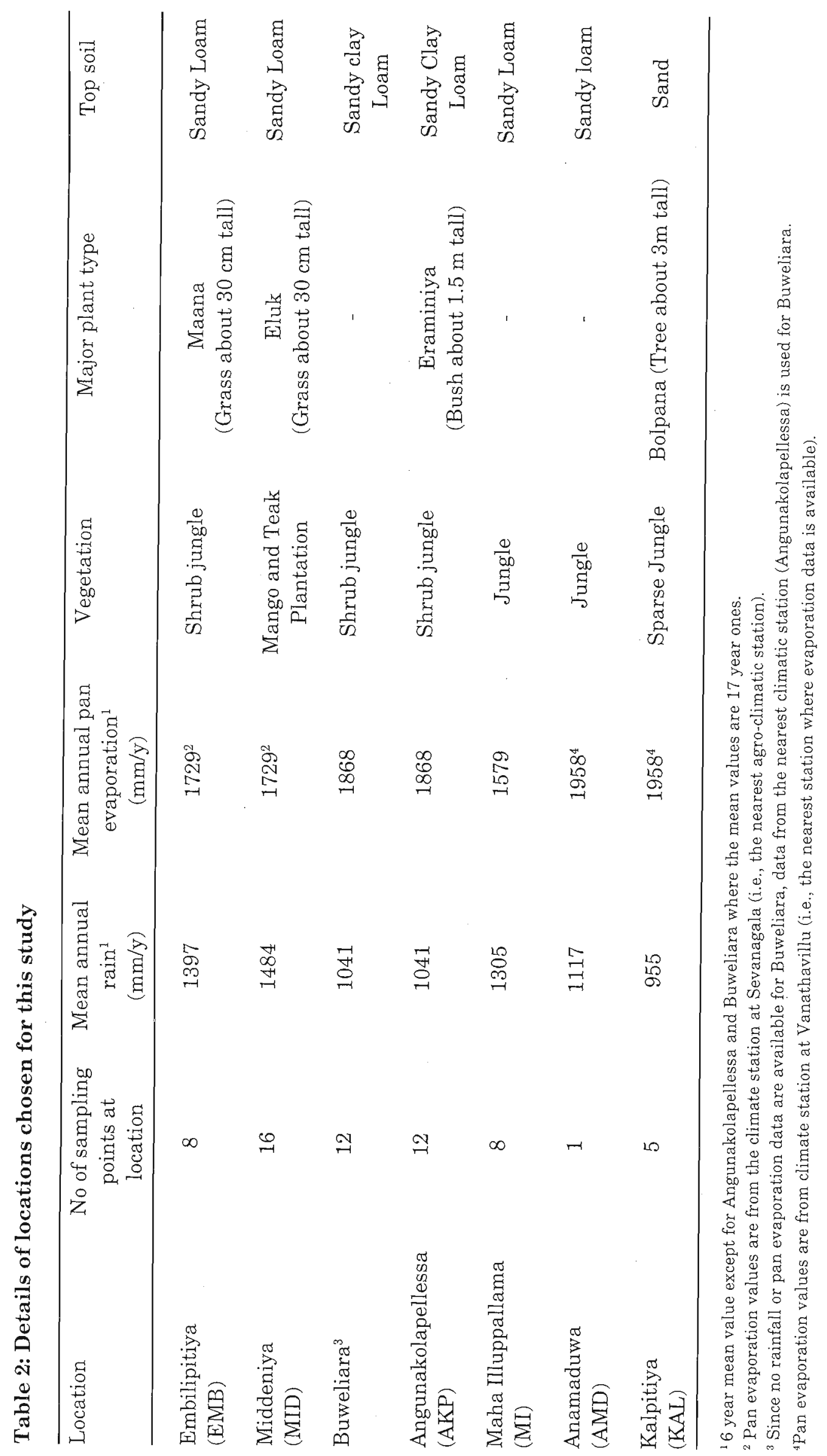




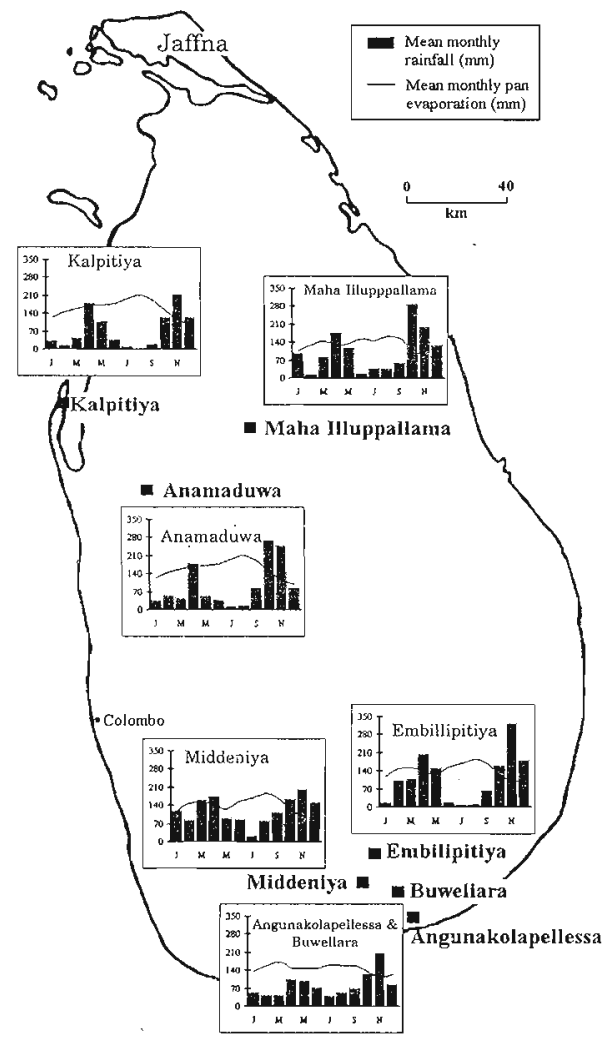

Figure 2: Study locations chosen for this study (distribution of annual rainfall and evaporation are also shown for each location)

Determination of available water capacity of soil in the root zone: The field capacity $(\mathrm{FC})$ and the permanent wilting point (PWP) of soil samples at each sampling point in each site were obtained using the pressure plate apparatus at 0.1 bar (10 $\left.\mathrm{kN} / \mathrm{m}^{2}\right)$ and 15 bar $\left(1500 \mathrm{kN} / \mathrm{m}^{2}\right)$ respectively as these pressures are usually taken to correspond to FC \& PWP. The depth of root zone at each sampling point was measured in the field by physically observing the root systems. The rainfall and pan evaporation data for at least 6 continuous years were obtained from the Department of Meteorology and the Agriculture Research Stations at respective locations. Details of all the above data had been given earlier. ${ }^{5}$

A suitable soil water budgeting model to estimate recharge in the dry zone: Before formulating a soil water budgeting model, it is necessary to consider the important specific components (apart from rainfall and actual evapotranspiration which are important anywhere in the world) of the hydrological cycle for the study areas.
Interception: In the dry zone, interception of rainfall is significant because, (a) the vegetation of the dry zone is described as a "2 storey" vegetation ${ }^{12}$ consisting of taller trees and shorter bushes and a layer of leaf litter on the ground, effectively forming 3 different stages for rain interception, (b) trees in tropical forests have large trunks and branches and therefore large surface areas ${ }^{13}$ resulting in significant amounts of interception and (c) rainfall tend to be of high intensity and short duration, allowing sufficient time for leaves and bark to dry thus intercepting a significant amount of rain from each rainfall event.

Runoff: Runoff is an important component of a soil water budget in the dry zone because, (a) the soil surface in the dry zone is generally hard which could be the result of drying out of the sealed layer formed during heavy rains where finer soil particles are washed into the cavities between coarse particles ${ }^{14}$ thus allowing significant runoff, (b) high rainfall intensities, as seen from Fig. 3, where more than $60 \%$ of the rains at all locations are rains with amounts between $2 \mathrm{~mm} / \mathrm{d}$ and 20 $\mathrm{mm} / \mathrm{d}$. It is likely that a $2 \mathrm{~mm}$ and a $20 \mathrm{~mm}$ rain would have durations of about 2 and 30 minutes respectively (as surfaced with the discussions with many people including some officers in the Department of Meteorology, Sri Lanka) in the dry zone and therefore, it is possible that more than $60 \%$ of the rains have intensities between $2 \mathrm{~mm} /$ 2 minutes $=60 \mathrm{~mm} / \mathrm{h}$ and $20 \mathrm{~mm} / 30$ minutes $=40$ $\mathrm{mm} / \mathrm{h}$, (c) low infiltration capacities of soil compared to rain intensities (Fig. 4), where more than $85 \%$ of infiltration capacity values are less than $40 \mathrm{~mm} / \mathrm{h}$ (d) flow in streams in the dry zone are significantly higher during rainy days than in other days, suggesting higher surface runoff than base flow. In fact most of these streams dry up soon after rains and (e) a high portion $(37.5 \%)^{15}$ of rain flowing in rivers in the dry zone. This figure comprises both base flow and runoff, but, from item (d) above, it is seen that runoff is the major component.

Preferential flow: Preferential flow is the flow of water through cracks, joints and worm and root channels in the soil by passing the soil matrix. Generally, these flow paths are predominant in the shallow unsaturated zone. In the dry zone the preferential flow is likely to occur because: 


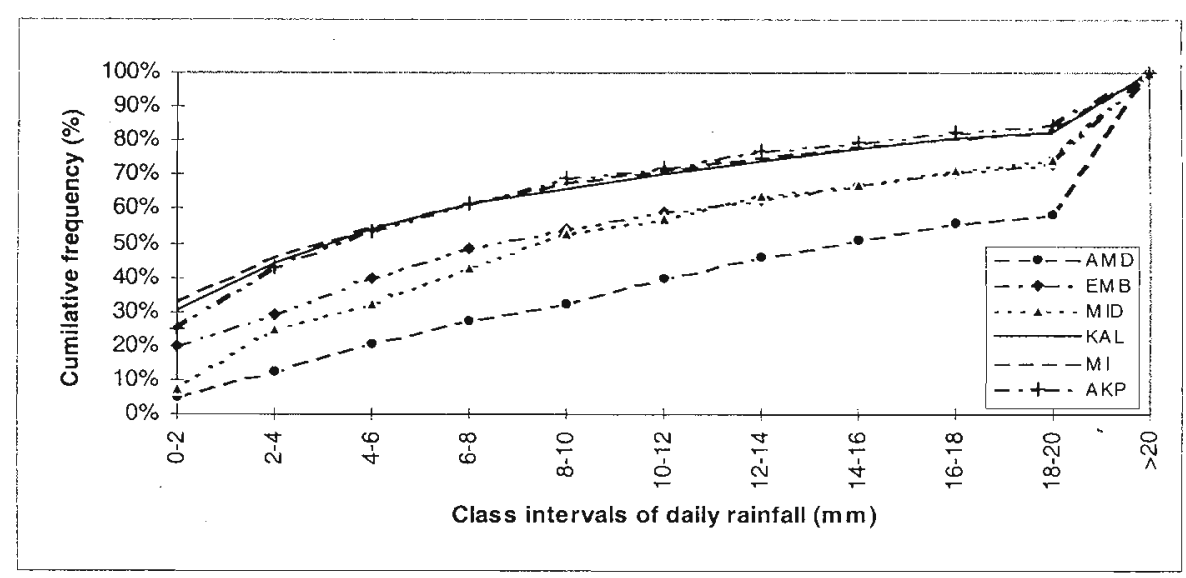

Figure 3: Cumulative frequency distribution of rainfall at the 7 sites in the dry zone of Sri Lanka

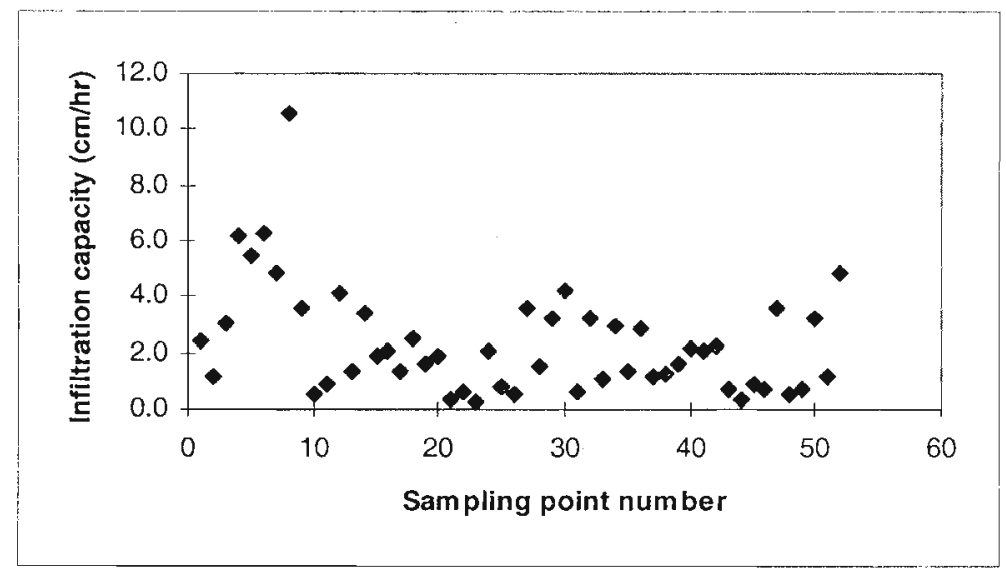

Figure 4: Infiltration capacity of surface soils at all the sites (except at Kalpitiya)

(Note: some infiltration capacities in Fig. 4 are close to the initial infiltration rate, as only 2 or 3 readings were obtained at these sampling points even after carrying out the test for 12 hours due to very slow infiltration. All the tests were carried out until a constant rate of infiltration was reached or in instances where the infiltration rate was very slow, the tests were stopped after 12 hours).

(a) the soils found in the dry zone are more clayey than sandy and structured clayey soils are more likely to have preferential flow, through cracks which often remain open even when wetted,

b) some of the values of infiltration rates (Fig. 4) are rather high for the textures encountered, which may be due to the presence of preferential flow paths and

(c) immediate increase of water table levels in the piezometers even during the dry period where it is likely that a soil moisture deficit exists. ${ }^{5}$
It must be noted here that, for preferential flow to be important (from the point of view of a soil water budget), it is not necessary for these paths to be deep, as the amount of water by passing the soil matrix, even though small, may affect actual evapotranspiration, and hence recharge.

Therefore, it is concluded that all three processes of interception, runoff and preferential flow need to be considered in estimating recharge with a soil water balance in the dry zone of Sri Lanka. 
Formulation of the model: Having identified the essential components, a simple soil water budget model is formulated as described below.

To estimate the actual evapotranspiration, the model shown in equation 3 is used.

If $\mathrm{SMD}<\mathrm{SMDcd}$ or $\mathrm{ETp}<=\mathrm{R}, \mathrm{ETa}=\mathrm{ETp}$

If $\mathrm{AWC}<\mathrm{SMD}<=\mathrm{SMDcd}$

and $\mathrm{ETp}>\mathrm{R}, \mathrm{ETa}=\mathrm{R}+\mathrm{F}^{*}(\mathrm{ETp}-\mathrm{R})$

If $\mathrm{SMD}=\mathrm{AWC}$ and $\mathrm{ETp}>\mathrm{R}, \mathrm{ETa}=\mathrm{R}$

where SMDcd is the critical soil moisture deficit beyond which the actual evapotranspiration begins to fall below the potential evapotranspiration. To estimate the function $\mathrm{F}$, the model described in the publication Yeild Response to Water ${ }^{15}$ is selected. This model is shown in graphical form in Fig. 5.

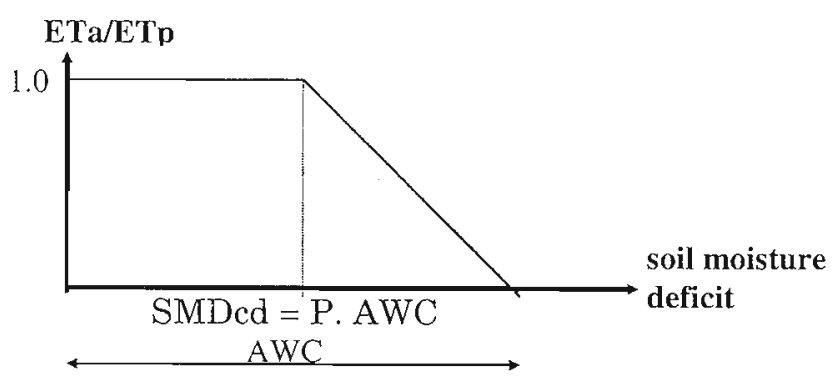

Figure 5: Model by Doorenbos and Kassam ${ }^{16}$ to estimate actual evapotranspiration (AWC = Available Water Capacity = maximum soil moisture deficit possible in the root zone)

To estimate interception (I) the simple model in equation 4 is used.

$R \leq I_{s c} ; I=R$

$R>I_{s c} ; I=I_{s c}$

Here $I_{s c}$ is the interception storage capacity value, usually ranging from about 0.5 to $11.0 \mathrm{~mm} / \mathrm{d}^{5}$

In the absence of necessary information to model on runoff $(\mathrm{RO})$ and preferential flow $(\mathrm{PF})$ in the dry zone, very simple models as shown in equations 5 and 6 are chosen to estimate these variables respectively.
$R O=R O_{c}\left(R-R O_{t}\right)$
$P F=P F_{c}\left(R-P F_{t}\right)$

$\mathrm{RO}_{\mathrm{c}}$ and $\mathrm{PF}_{\mathrm{c}}$ are dimensionless coefficients and $\mathrm{RO}_{\mathrm{t}}$ and $\mathrm{PF}_{\mathrm{t}}$ are threshold values of daily rainfall above which runoff and preferential flow are assumed to occur.

Therefore, considering the above sub models for actual evapotranspiration, interception, runoff and preferential flow, a flow chart for a soil water budgeting model to estimate recharge in the dry zone is shown in Fig. 6.

Validating the soil water budget model: To validate the soil water budget model formulated, it was not possible to obtain data for a recharge study in conditions similar to that of the dry zone in Sri Lanka. However, for Silsoe in UK, Ngwazi Tea Research Unit in Tanzania (with a uni-modal rainfall distribution and an almost uniform potential evapotranspiration distribution in the year; Stephens, Personal Communication, 1991) and for Nguru in Nigeria (with a uni-modal rainfall distribution and an almost uniform potential evapotranspiration distribution in the year; Carter, Personal Communication, 1994), data and estimates/experimentally obtained values of recharge and/or soil moisture contents are available as shown in Table 3. Although the climates of Ngwazi and Nguru are not the best climates to use a soil water balance (as errors in actual evapotranspiration could be high) these data are still used in checking the soil water budget model in the absence of any other suitable data.

As can be seen from Table 3, recharge estimates for Silsoe and Nguru obtained by soil water budget are comparable with those obtained by different workers. Fig. 7 shows the experimentally obtained soil moisture deficit (obtained by measuring the volumetric soil moisture content with a neutron probe at every $200 \mathrm{~mm}$ in the whole $5 \mathrm{~m}$ of the root zone and by knowing the field capacity values for each soil type in the profile ${ }^{17}$ ) and the soil water budgeting model calculated soil moisture deficit and it is seen that agreement between the two are excellent. Therefore, it is concluded that the soil water budget model formulated appears to yield estimates of recharge with satisfactory accuracy. 


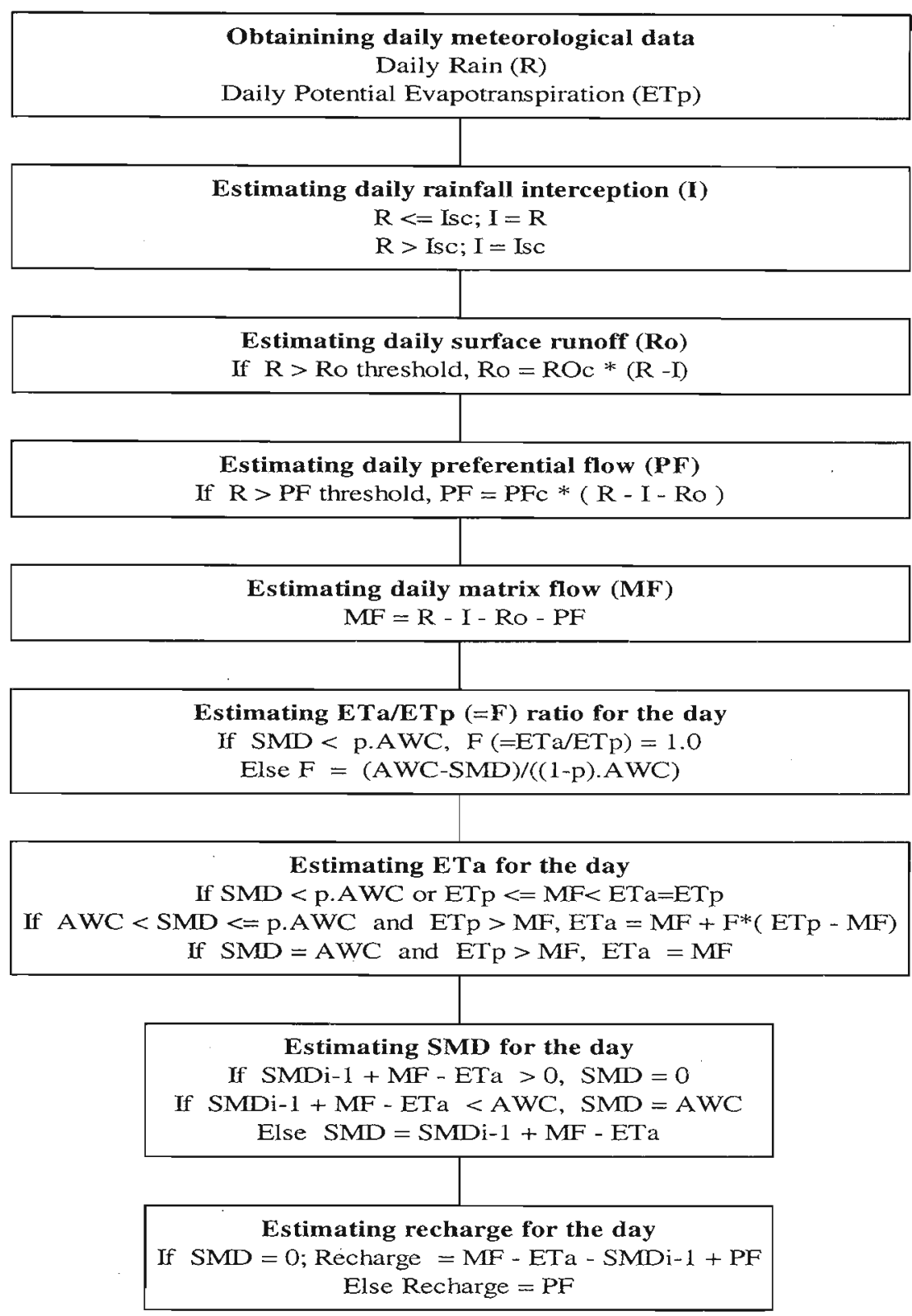

Figure 6: Flow chart of the soil water budgeting model suitable for the dry zone

Estimates of recharge with the soil water budget model formulated: To estimate recharge in the dry zone with the formulated soil water budget model, data and values for model parameters are required. The data required are rainfall, potential evapotranspiration and available water capacity of soil in the root zone. The model parameters required are interception storage capacity, runoff threshold, runoff coefficient, preferential flow threshold, preferential flow coefficient and root constant.Rainfall and potential evapotranspiration data are usually available and available water capacity data can be experimentally determined (as in this study). However, model parameters need to be determined for each site from hydrogeological information of the area.

One way of determining the values for model parameters is by calibrating the soil water budget with estimates of recharge from another method, soil moisture data, stream flow data or water table data (if the water table is shallow and actual recharge is similar to potential recharge). However, for the model parameters to be realistic these calibration data must cover at least a wet, dry average year (with respect to rainfall). Since 
such data are not available for the present study, a different approach is to see the sensitivity of each model parameter and identify the important parameters and attempt to determine these important parameters only. However, for the sensitivity analysis approximate values for model parameters are still required. The last 6 columns of Table 4 show the likely ranges of values for model parameters (and also how they were arrived at) for each location in the dry zone of Sri Lanka.

Sensitivity of model parameters: The sensitivity of potential recharge to model parameters are shown in Fig. 8 for the location Angunakolapellessa. Table 5 summarises the sensitivity of recharge when the particular model parameter is changed by $\pm 10 \%$. Considering the model parameters which will effect a change in recharge by more than $2 \%$ as sensitive, Table 6 shows the ranges of model parameters that need to be considered in estimating recharge for the dry zone for the different locations.

With the model parameter combinations in Table 6, the range of estimate of recharge at each site in the dry zone of Sri Lanka is shown in Table 7.

From Table 7, it is evident that the range of recharge values for a site, obtainable with the data available with the soil water budgeting method is rather wide and hence is of limited use. This result however, demonstrates the importance of estimating the model parameters accurately as even the narrow ranges of model parameters used in the soil water budget model (Table 6), result in rather wide ranges of estimates for recharge. Therefore, it is concluded that for the use of a soil water budgeting model to estimate recharge in the dry zone of Sri Lanka; it is necessary to be able to use accurate model parameters.

\section{DISCUSSION}

This paper evaluates the use of a simple soil water budgeting model in estimating recharge in the dry zone of Sri Lanka. A simple soil water budget model is formulated by reviewing the documented cases of estimating recharge with a soil water budget and also by considering the important components of the water balance in the dry zone.
With the data and information available on different components of the water budget in the dry zone, the estimates obtained are wide ranges rather than single values with limited use. This is because of the uncertainties involved in estimating interception, runoff, actual evapotranspiration and preferential flow in a soil water budget, which results from a lack of information about modelling these components and also from a lack of suitable calibration data.

One way of narrowing down the estimate of recharge is to calibrate the model with say soil moisture data, groundwater level data and/or stream flow data. Here, the unknown parameters (like Isc, Roc, Rot etc) are slightly changed until the measured soil moisture data (or groundwater level or runoff) gives the best correlation with the model estimated soil moisture data (or groundwater level or runoff estimated by the model as the case may be). The more these records are available and longer the period of data availability, the more it will be possible to fine tune the uncertainties in the aforesaid parameters, thus narrowing down the estimate of recharge. Therefore, it is necessary that action is taken to have a good database of hydrogeological data such as flow records of important streams and groundwater levels at important locations, so that in future, soil water budget models would yield more meaningful estimates of recharge for the dry zone.

These results are likely to be obtained, even if different approaches are used for modelling the components of the water budget and is not due to the simple model used in this study. In fact, the estimates are likely to be even wider if more complex models are used for these components.

\section{References}

1. Senerath D. C. H. (1990a). Some Management Aspects in the Use of Groundwater. In: Irrigation \& Water Resources, (Ed. E. R. N. Gunawardena), Department of Agricultural Engineering, University of Peradeniya, Sri Lanka.

2. Allison G. B., Gee G. W. \& Tyler S. W. (1994). Vadose-Zone Techniques for Estimating Groundwater Recharge in Arid and Semiarid 


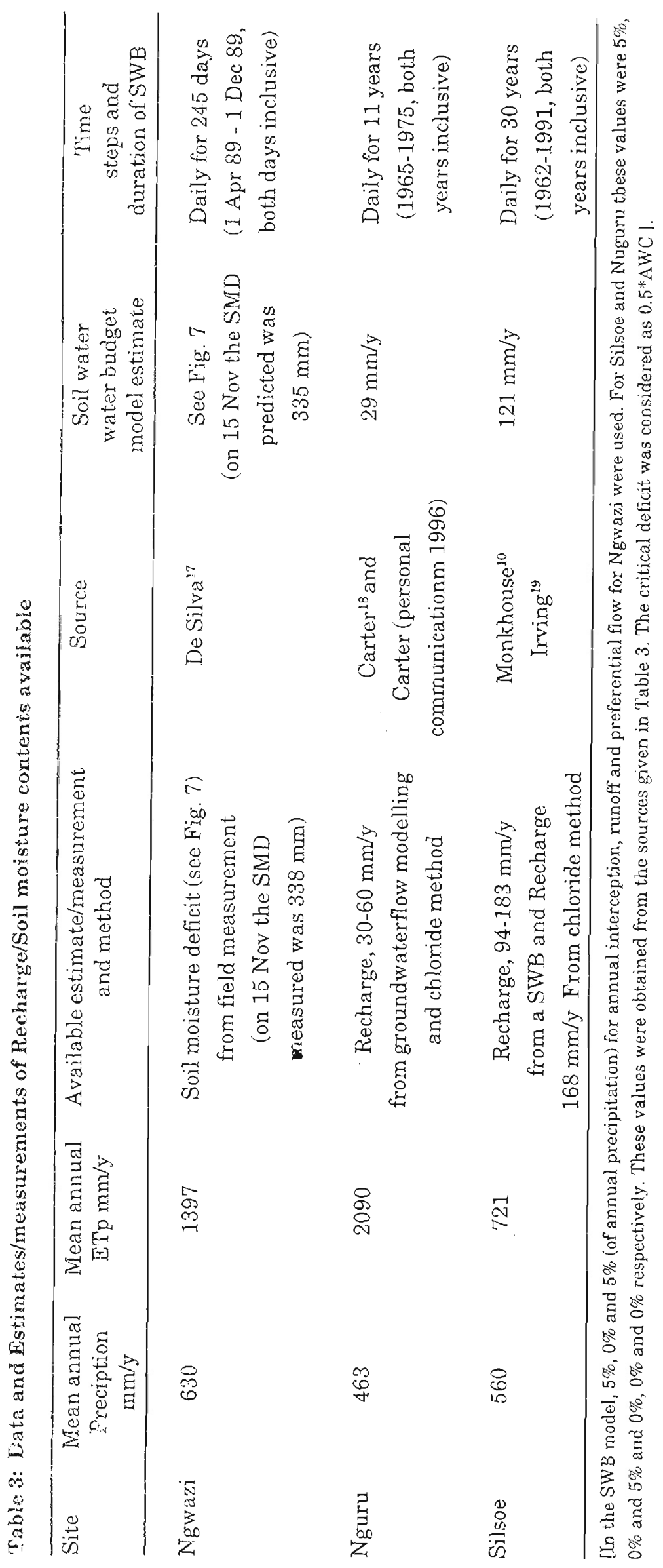


Rain, Experimentally observed \& SWB estimated SMD at Ngwazi Tea Research Unit in Tanzania, 1989

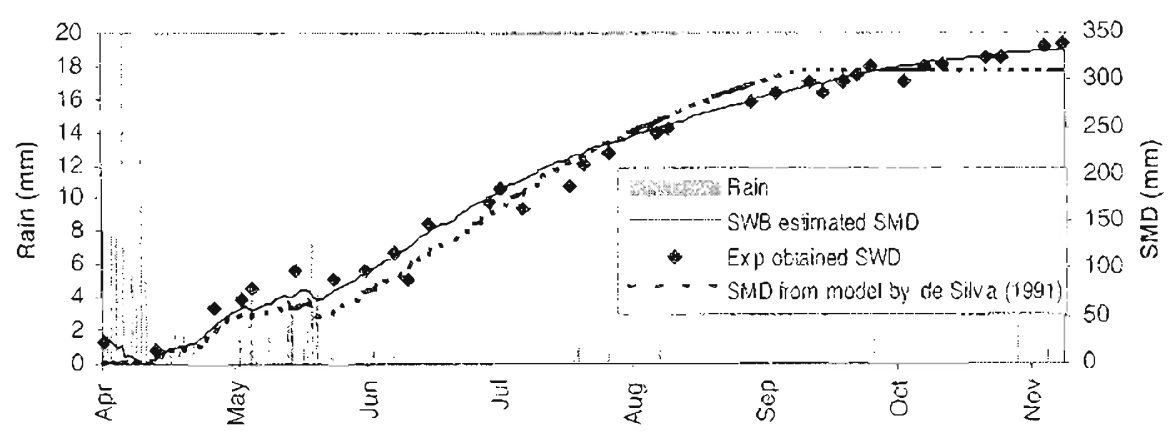

Figure 7: Experimental and soil water budget model estimated soil moisture deficit

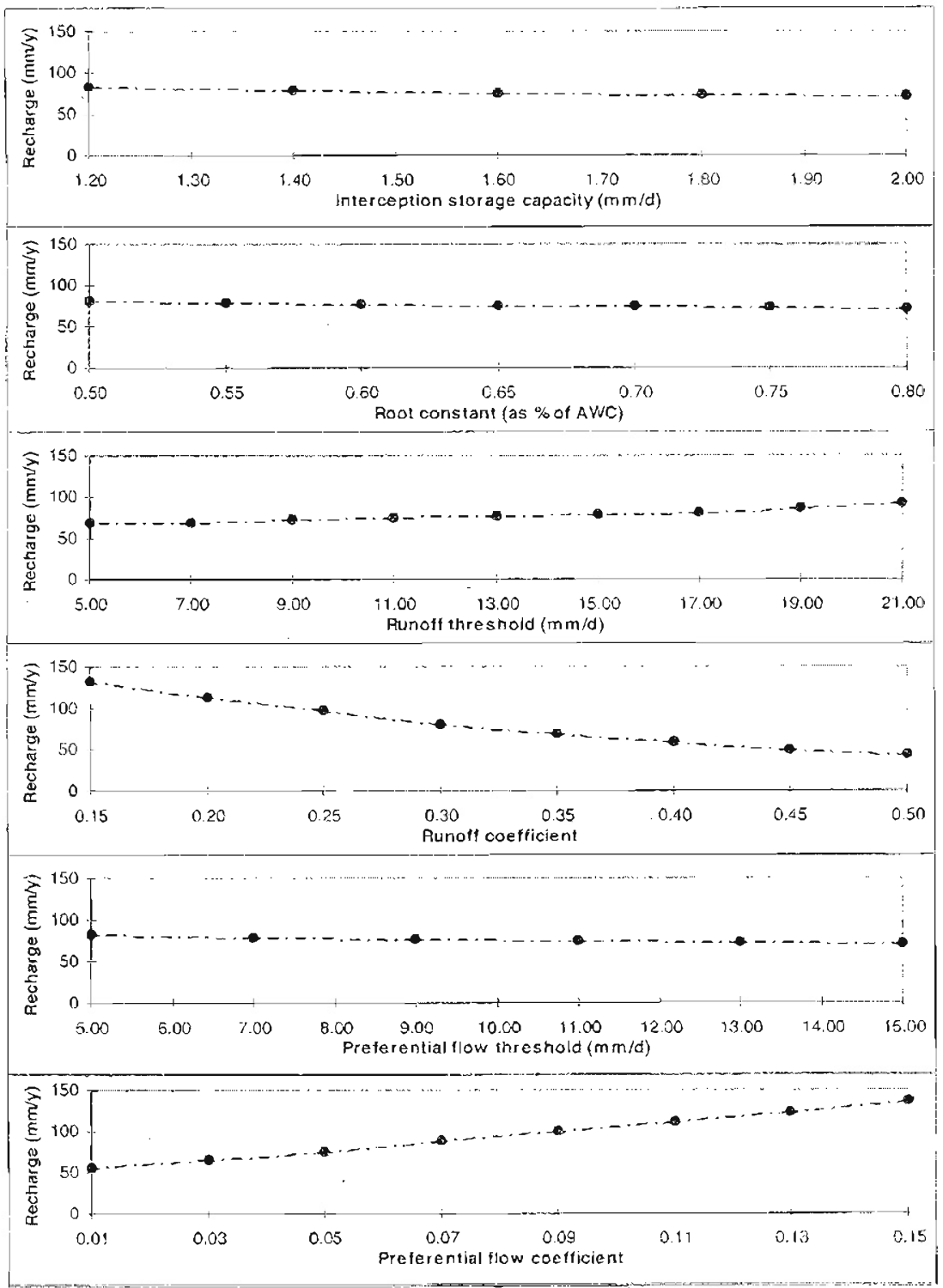

Figure 8: Sensitivity of potential recharge to model parameters at Angunakolapellessa

IIn Fig. 8, AWC=101 mm which is the average AWC for site AKP. The model parameter combination is $0.65,1.6,12.5,0.32$, 12.5 and 0.05 for $R C$, Jsc, $R O t, R O c, P F t$ and $P F c$ respectively]. 


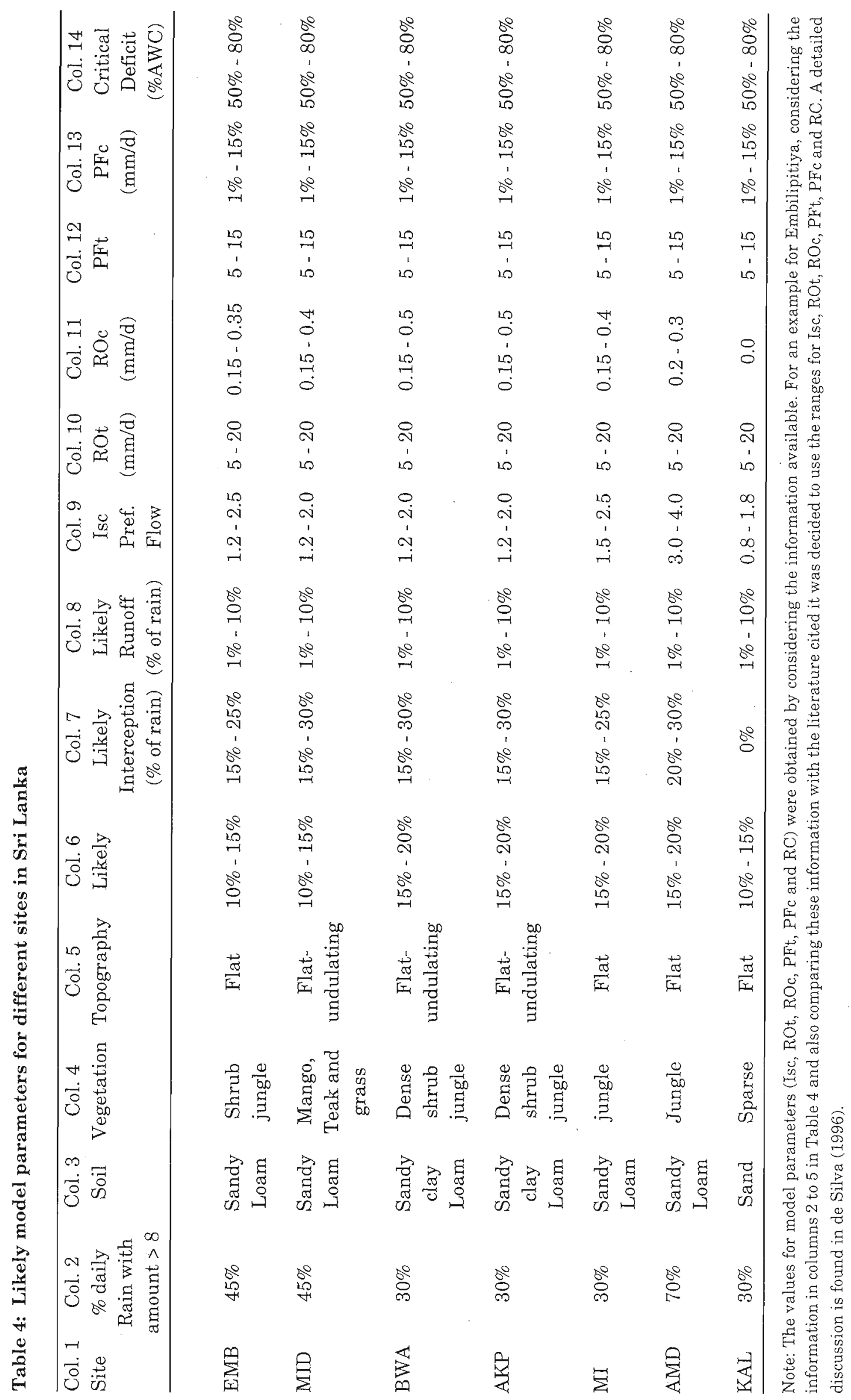




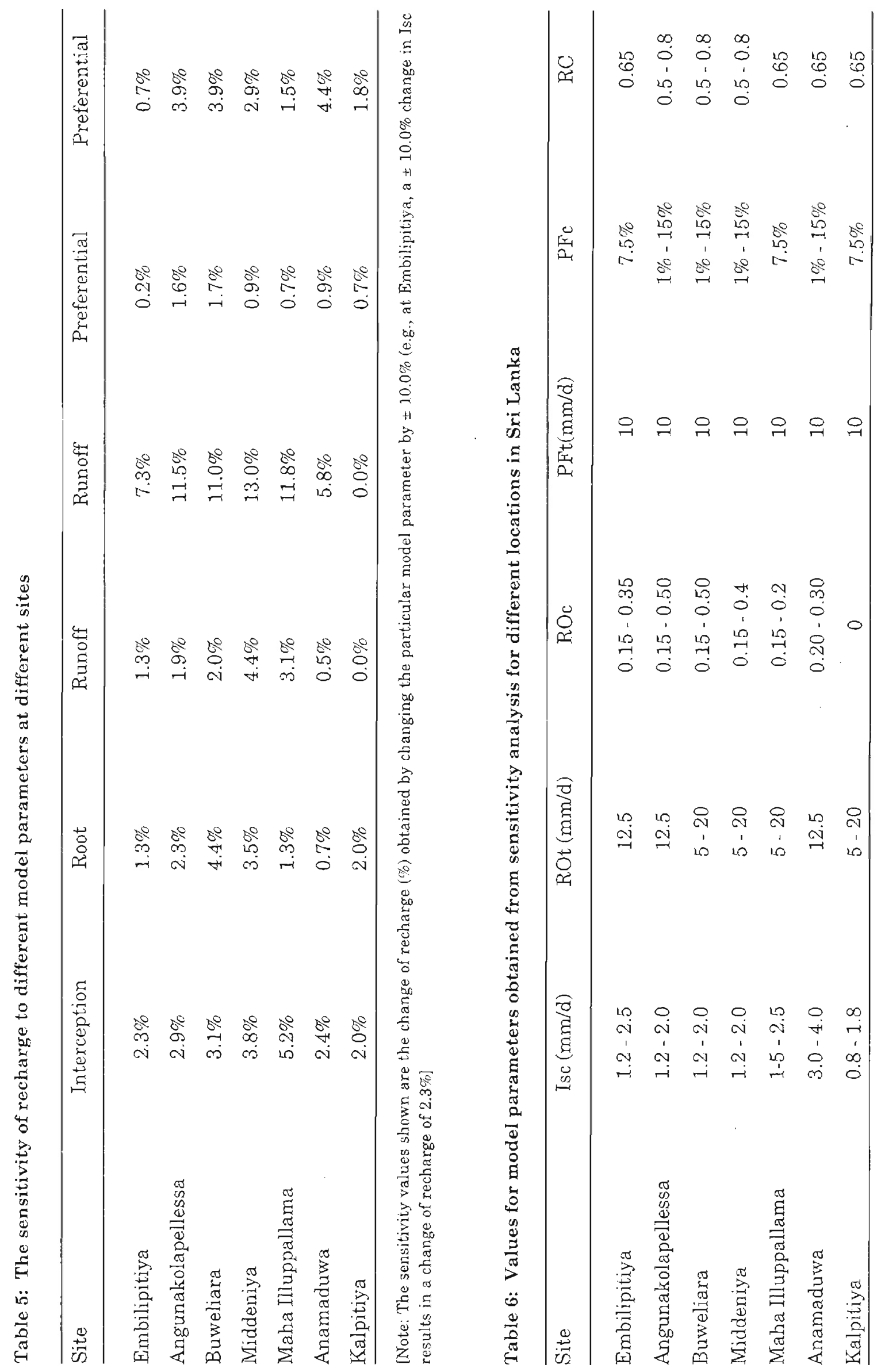


Table 7: Range of recharge values possible from the soil water budget with combinations of model parameters in Table 6 for sites in Sri Lanka

\begin{tabular}{|c|c|c|c|}
\hline Site & Average $^{1}$ recharge & Minimum recharge & Maximum recharge \\
\hline Embilipitiya & 275 & 80 & 391 \\
\hline Angunakolapellessa & 76 & 7 & 244 \\
\hline Anamaduwa & 100 & 46 & 237 \\
\hline Buweliara & 69 & 7 & 235 \\
\hline Maha Illuppallama & 123 & 16 & 340 \\
\hline Middeniya & 121 & 12 & 348 \\
\hline Kalpitiya $^{2}$ & 128 & 94 & 195 \\
\hline
\end{tabular}

1 Average recharge estimates were obtained by using the middle values of parameters in Table 6 .

2 Field capacity and permanent wilting point values are assumed as $14 \%$ and $4 \%$ by volume respectively for Kalpitiya as no experimental data are available. ${ }^{20}$ Also the depth of root zone is considered as $1.5 \mathrm{~m}$.

Regions. Soil Science Society of America Journal 58: 6-14.

3. Hendricks J. M. H. \& Walker G. R. (1997). Recharge of Phreatic Aquifers in Arid \& SemiArid areas. A.A. Balkema Rotterdam.

4. Lerner D. N., Issar A. S. \& Simmers I. (1990). Groundwater Recharge: $A$ Guide to Understanding \& Estimating Natural Recharge. International Association of Hydrogeologists, Hannover.

5. De Silva R. P. (1996). Estimating Groundwater Recharge in the Dry Zone of Sri Lanka with Special Emphasis on Spatial Variability. Unpublished PhD Thesis, Silsoe College, Cranfield University, UK.

6. Lloyd J. W. , Drennan D. S. H. \& Bennell B. M. U. (1966). A Groundwater Recharge Study in North Eastern Jordan. Proceedings of Institution of Civil Engineers 35: 615-631.

7. Howard K. F. \& Karundu J. (1992). Constraints on the Exploitation of Basement aquifers in East Africa - Water Balance Implications and the Role of the Regolith. Journal of Hydrology 139: 183196.

8. Senerath D. C. H. (1990b). Two case studies in estimation of groundwater recharge. Groundwater Monitoring \& Management IAHS Publication no.173, UK.
9. Headworth H. G. (1970). The Selection of Root Constants for The Calculation of Actual Evaporation and Infiltration for Chalk Catchments. Journal of Institution of Water Engineers 24: 431-446.

10. Monkhouse R. A. (1974). An assessment of the groundwater resources of the lower Greensand in the Cambridge - Bedford Region. Water Resources Board, Reading, UK.

11. Rushton K. R. \& Ward C. (1979). The Estimation of Groundwater Recharge. Journal of Hydrology 41: 345-361.

12. Fernando S. N. U. (1967). Ceylon Soils, Swabhasha Printers, Sri Lanka.

13. Herwitz S. R. (1985). Interception Storage Capacities of 'Tropical Rain forest Canopy Trees. Journal of Hydrology 77: 237-252.

14. Brady N. C. \& Weil R. R. (1996). The Nature \& Properties of Soils (eleventh edition). PrenticeHall Inc., USA.

15. Arumugam S. (1969). Water Resources of Ceylon. Water Resources Board, Sri Lanka.

16. Doorenbos J. \& Kassam A. H. (1979). Yield Response to Water. FAO, Rome.

17. De Silva R. P. (1991). A Multi Layer Soil Water Use Model for Tea. Unpublished MSc Thesis, Silsoe College, Cranfield University, UK. 
18. Carter R. C., Morgulis E. D., Dottridge J. \& Agbo J. U. (1994). Groundwater Modelling with Limited Data: A Case Study in a Semi-Arid Dunefield of Northeast Nigeria. Quarterly Journal of Engineering Geology 27: S85-S94.

19. Irving W. M. (1982). Chloride Ion Concentration as an Aid to Estimating Recharge to the Woburn Sands. Quarterly Journal of Engineering Geology 15: $47-54$.
20. Booker Tropical Soil Manual, (1984). A Handbook for Soil Survey and Agricultural Land Evaluation in the Tropics and Sub Tropics. (Ed. J. R. Landon), Booker Agriculture Institution, London, UK. 